\title{
EL MITO NETIANA
}

REMEDIOS ZAFRA

Universidad de Sevilla

\section{NOTA INTRODUCTORIA: TAXONOMÍA NETIANAS}

"Las netianas se dividen en (a) pertenecientes a Microsoft, (b) latentes, (c) inventadas, (d) prosopon, (e) cyborgs, ( $f$ ) "fabulosas", (g) sujetos Google, (h) incluidas en esta clasificación, (i) chateadoras compulsivas, (j) incontables, (k) descritas mediante letra Times New Roman, (l) etcétera, (m) que acaban de entrar en Silicon Valley (n) que viven lo que una mosca.... ${ }^{1}$

No debe extrañar que las netianas se presenten y hablen irónicamente de sí mismas y de Internet a partir de unas categorías aparentemente ridículas (parodiadas de la taxonomía de animales hecha por Borges en «El idioma analítico de John Wilkins»). Desvelan así la arbitrariedad del intento de clasificación y su afectación identitaria. Aunque tomar conciencia de ello no les redime de quedar -performativa, pero también perversamente- sentenciadas a las identidades que dicha enunciación sugiere. En dicho juego constitutivo las netianas experimentan y reflexionan sobre cómo el hecho de enunciarse en femenino afecta a lo que son y a lo que pueden ser en el ciberespacio, es decir a las maneras en que Internet condiciona el ser y el hacer «mujer» a partir de nuestras identidades ("lo que la sociedad hace con nosotras») y también de nuestras subjetividades («lo que nosotras hacemos con lo que la sociedad hace con nosotras»).

\section{MITOPOIESIS. EL MITO NETIANA COMO GENERADOR DE SUBJETIVIDAD POLÍTICA EN INTERNET}

Son varias las autoras que han animado la creación de mitos como manera efectiva de subvertir la hegemonía representativa del patriarcado. Las netianas

1. «Los animales se dividen en (a) pertenecientes al emperador, (b) embalsamados, (c) amaestrados, (d) lechones, (e) sirenas, (f) fabulosos, (g) perros sueltos, (h) incluidos en esta clasificación, (i) que se agitan como locos, (j) innumerables, (k) dibujados con un pincel finísimo de pelo de camello,

(l) etcétera, (m) que acaban de romper el jarrón, (n) que de lejos parecen moscas...», BORGES, Jorge Luis: "El idioma analítico de John Wilkins», en Otras inquisiciones, Madrid, Alianza, 1997 (1952), pp. 154-161. 
se proclaman herederas de estos mitos y pretenden ir más allá de la producción teórica y artística de una quimera. La producción netiana se hace en el mismo territorio del discurso al que pretende modificar, el ensayístico.

Netiana: sujeto posthumano e inmaterial que $n(h) a c e$ en Internet. Figuración teorética alternativa del sujeto en red. Ficción política que rebasa las fronteras de género y que sugiere nuevas preguntas sobre las formas de ser y de relacionarnos en el universo on line. La netiana es una confrontación con lo dominante.

La netiana, heredera del cyborg de Haraway ${ }^{2}$ y del sujeto nómade de Braidotti ${ }^{3}$, es una criatura deseante y productiva, poéticamente fundada en el territorio de lo facticio. Es además una figura irónica ciberfeminista que advierte de los nuevos riesgos de Internet para la producción emancipadora del sujeto contemporáneo «mujer». En su deriva por el medio Internet, esboza preguntas y apunta desafíos feministas acercándose a lo visual-digital como una nueva localización del poder, al cuerpo conectado como un campo de inscripción de códigos sociosimbólicos que converge cada vez más con la máquina, al género como algo construible en la nueva complejidad del contexto on line. Desde la convicción de que, a través de la crítica y la ironía subversivas en combinación con las más cercanas experiencias vitales de las mujeres que habitan en Internet, podremos sugerir estrategias para una acción política eficaz y creativa en el mundo en red del que ya formamos parte.

En esta línea, y para situar nuestra figuración, habríamos de plantearnos algunas interrogantes que nos ayuden a entender mejor las condiciones que rodean al mito netiana. En primer lugar, teniendo en cuenta que la netiana es una entidad facticia que se produce en Internet y que allí no tenemos cuerpo físico con el que interactuar, tal vez debiéramos comenzar preguntándonos ¡cuáles pueden ser los límites (si existen) materiales y discursivos del sujeto en la red? Estos límites en el mundo físico podrían venir establecidos por el efecto forzado del sexo, tal como sugería Butler en Cuerpos que importan ${ }^{4}$, y de la misma manera que el sexo regula los términos que materializan los cuerpos se confirma la validez (o no) de éstos atendiendo a modelos hegemónicos heterosexuales. Pero, cuando las diferencias físicas y sus variables se difuminan o se anulan mediante la ocultación de los cuerpos, podemos vacilar sobre el lugar que ocupan los límites discursivos y materiales del sexo en Internet... Los cuerpos ¿qué importan? en un medio donde el sujeto se produce a través de una interfaz ¿sería este proceso desmaterializador el propulsor de una nueva epistemología del sujeto también en lo referente al sexo? En este caso, parece que el sexo no sería excluido de la esfera del cuerpo, sino más bien al contrario, el cuerpo sería excluido de la esfera del sexo, de su materialización ideológica

2. HaraWAY, Donna: Ciencia, cyborg y mujeres. La reinvención de la naturaleza, Madrid, Cátedra, 1995.

3. BRAIDOTTI, Rosi: Sujetos nómades, Barcelona, Paidós, 2000.

4. BUtLER, Judith: Cuerpos que importan. Sobre los limites materiales y discursivos del "sexo", Barcelona, Paidós, 2002, pp. 17-18. 
en el género que, liberado, adopta fórmulas desmaterializadas y no esencialistas. En este contexto, el retorno perturbador no sería por tanto del sexo al cuerpo sino del cuerpo al sexo.

Liberados temporalmente de los lastres que lo corporal nos plantea, la alternancia de procesos de desmaterialización y reencarnación afectaría tal vez a un nuevo horizonte simbólico del que se impregnan (se hacen) las netianas. En este carácter reversible propio de la conducta del sujeto on line estaría, de momento, una singularidad de la netiana (que se prolonga hasta las ficciones más futuristas donde existen realidades en conflicto, la orgánica del sujeto físico y la digital inducida por la máquina). Esta singularidad de la netiana trataría de la alternancia entre diversas formas de vida propiciadas por estar o no estar conectado. Por ahora, la vida on line, sea cual fuere la complejidad-sensibilidad de la pantallainterfaz que nos ponga en contacto con otros, es temporal. Las vidas virtuales, bien mediante avatares de texto o mediante sofisticados cuerpos de videojuego, tienen una caducidad y precisan de una vuelta periódica al cuerpo.

Nuestros cuerpos netianas (de haberlos) no podrían ser entendidos como una categoría biológica, sí tal vez como una performatividad, una nueva variedad de cuerpos-verbo de apariencia múltiple y cambiante que al enunciarse están ya realizándose. En esta línea surgiría otra cuestión, si (recordamos a Butler) la práctica reiterativa y referencial mediante la que el discurso produce los efectos que nombra nos lleva a pensar en la performatividad de las normas reguladoras del sexo y, por consiguiente, en cómo éstas propician la materialidad de la diferencia sexual en función de la hegemonía heterosexual, ¿cómo operaría esta materialidad en la netiana? El cuerpo, o la corporización del sujeto, sugiere Braidotti ${ }^{5}$, «no debe entenderse ni como una categoría biológica ni como una categoría sociológica, sino más bien como un punto de superposición entre lo físico, lo simbólico y lo sociológico». La materialidad de la diferencia sexual no estaría limitada al cuerpo físico, de la misma manera que el poder no está concentrado en lugares fijos. De hecho, la base de la mayoría de redefiniciones feministas de la subjetividad pone énfasis en la estructura sexualmente diferenciada y corporizada del sujeto hablante. Para Braidotti, por ejemplo, replantear las raíces corpóreas de la subjetividad es el punto de partida para iniciar su proyecto epistemológico del nomadismo, lo cual nos lleva a observar que para la cualidad nómade de las netianas (cuya identidad sexual y demás características escritas en el cuerpo es artificial y potencialmente cambiante) este enfoque antiesencialista propio del nomadismo sería clave en el enlace de la materialidad de la diferencia sexual al cuerpo en Internet.

Por otra parte, aunque la materialidad sexual de los individuos está determinada por patrones hegemónicos heterosexuales en función de los cuáles se vinculan con las relaciones de poder, el hecho de que en Internet la materialización sexual sea (permítanme el juego retórico) «desmaterializada» no nos salvaguarda de esta acción hegemónica del poder, el territorio máquina-Internet no está

5. BRAIDOTTI, Rosi: Op. cit., pp. 29-30. 
exento de este dominio (de hecho, es una de sus creaciones). Y no lo está pese a habérsenos vendido como una utópica estructura horizontal y desjerarquizada. De hecho, la red ha sido entendida por muchas feministas (recordemos, por ejemplo, a Sadie Plant) como una oportunidad para la disidencia de la mujer, llevando en muchos casos a igualar feminización a digitalización.

La analogía sería sin duda sugerente y no puede ser menospreciada, no obstante las estructuras horizontales esconden las mismas ordenaciones de poder, más inquietantes si cabe en cuanto menos visibles. En los medios horizontales se establecen nuevas condiciones de relación intersubjetiva, pero también se da una relajación tramposa provocada por considerar que nuestra posición (en una red rizomática) es igualitaria a la del resto de sujetos en red. Tal vez ni una cosa ni la otra, ni es la panacea ni es "lo mismo de siempre». Serían distintas la forma de resistencia y acción y también las formas de poder. En este tipo de estructuras, las nuevas articulaciones del poder podrían ser representadas por formas dispersas, es decir, por la acción de pequeñas células de poder móviles, menos definidas pero que pueden ser igualmente eficaces en sus intentos de perpetuar los sistemas hegemónicos. También en estas formas de articularse el poder radican las nuevas maneras de constituirse la resistencia al mismo. Para contrarrestar estas estrategias de dominio diseminado, Braidotti plantea una gnoseología nómade radical, «una forma de resistencia al microfascismo, en la medida en que se concentra en la necesidad de un distanciamiento cualitativo de la hegemonía, sea ésta de las dimensiones que fuere y aunque sólo tenga un alcance local ${ }^{6}$. Buscar subjetividades feministas ${ }^{7}$ que subviertan esta consideración hegemónica del poder sería en este contexto cuestión prioritaria, así como convertirlas en lo que Haraway denomina "oradoras extáticas y alternativas»". Teniendo en cuenta que el contexto de 'cambio posible' pero también de 'alerta al riesgo hegemónico' tiende, por la propia estructura del poder, a desplazar la balanza hacia la alerta que advierte, en palabras de Braidotti: «(e)l presunto triunfo de la alta tecnología no se ve correspondido con un salto de la imagi-

6. Ibid., pp. 31-32.

7. «La gran cantidad de términos de que disponemos para describir esta nueva subjetividad feminista de la mujer es elocuente: Monique Witting decide representarla a través de lo «lesbiano»; Judith Butler se hace eco de esta idea al hablar de una "política paródica de la mascarada", otras, citando a Nancy Miller, prefieren describir el proceso como «devenir mujeres», en el sentido de los sujetos feministas mujeres de otra historia. De Lauretis habla del sujeto «excéntrico»; también se han descrito las subjetividades feministas alternativas como "compañeras de viaje» en un estado en tránsito, de paso. O como los «otros inapropiados» o como sujetos «poscoloniales» [...]. En estos últimos casos, se analiza el género en relación con otros asuntos geopolíticos atendiendo a los vínculos feministas trasnacionales». Ibid., pp. 27-28.

8. Señala Donna Haraway que precisamos figuras feministas de humanidad que sean capaces de enfrentarse a la figuración literal, figuras de resistencia que «estallen en enérgicos nuevos tropos, nueva figuras de dicción, nuevos términos de posibilidad histórica. Para que tenga lugar este proceso en el punto de inflexión de la crisis, donde todos los tropos vuelven a girar, necesitamos oradores extáticos» (HARAWAY, Donna: «Ecce homo, Ain't (Ar'n't) I a woman and inappropiate/d others. The Human in a Post-Humanist Landscape», en Judith Butler y Joan Scott (comp.): Feminists theorize the political, Londres y Nueva York, Routledge, 1992, p. 86). 
nación humana encaminado a crear nuevas imágenes y representaciones. Más bien al contrario, lo que veo es la repetición de temas y clichés muy antiguos, disfrazados de nuevos avances tecnológicos. Esto demuestra que hace falta algo más que una máquina para alterar verdaderamente los modelos de pensamiento y hábitos mentales»" ${ }^{9}$. Bajo esta demanda n(h)acen las netianas.

\section{LAS NETIANAS EN LA PRÁCTICA ARTÍSTICA CIBERFEMINISTA}

De la misma manera que el vínculo mujer artista/mujer feminista ha sido muy frecuente en las últimas décadas, sobre todo en el proceso de toma de conciencia colectiva, también lo ha sido el interés de las artistas feministas por Internet (y en general por los nuevos medios de comunicación en los que difundir sus reivindicaciones). No sin motivo, todo nuevo espacio adquiere un valor añadido para las mujeres en la búsqueda de métodos menos lastrados por la cultura patriarcal.

En el arte propio de la red, como en el mito netiana, se percibe un interés activo por la deconstrucción más característica de una acción feminizadora. Desde el origen del ciberfeminismo y el trabajo de las VNS Matrix pasando por las Internacionales Ciberfeministas lideradas por las $\mathrm{OBN}$, la visión de las artistas ha sido fundamental para el ideario ciberfeminista.

Las nuevas posibilidades de trabajo (tanto de producción como de distribución) brindadas por Internet permitieron a las artistas la creación de redes autónomas independientes de las estructuras jerárquicas propias de la instituciónArte. Por otra parte, la crítica a las lógicas lineales y excluyentes características de los discursos esencialistas tiene en los nuevos lenguajes de la red (basados en estructuras horizontales, fragmentadas e hipertextuales) una posibilidad de acción subversiva sin precedentes.

No obstante, tal vez el aspecto más interesante de la vinculación del trabajo creativo a la lucha política ciberfeminista venga del lado de la nueva responsabilidad de la creatividad en la época contemporánea en relación a la construcción de identidad (de ahí que las netianas se produzcan también en una intersección artística y ciberfeminista). Una nueva responsabilidad que nos hablaría de producción inmaterial, de la producción de deseo, de significado, de la producción de afectos y emotividad. Responsabilidad que se materializaría además en el uso de las industrias de la subjetividad para la construcción de dispositivos de colectividad y experiencia, donde se puede suscitar la inclusión y en su caso la crítica del resultado de construcción de identidad. De otro lado, no podemos olvidar que las políticas de producción de identidad vendrían determinadas por las nuevas condiciones para la producción del sujeto en un mundo en red, donde lo que somos es siempre facticio y el código produce identidades de usar y tirar. En esta línea, si consideramos las prácticas creativas como dispositivos de construcción crítica de subjetividad y sociabilidad, éstas pueden actuar como un importante instrumento, tal vez la más efectiva de las herramientas feministas que podamos imaginar.

9. BRAIDOTTI, Rosi: Cyberfeminism with a Difference, www.let.uu.nl/women_studies/rosi/ 
La práctica artística de las mujeres a través de las tecnologías desempeña un papel conocido dentro de nuestra cultura actual. Las mujeres artistas han sido pioneras en la producción con nuevas tecnologías. En ellas han visto una menor carga simbólica que en las prácticas y técnicas tradicionales. De hecho en los primeros años del net.art, también al principio del ciberfeminismo, éste era sin duda el aliciente: aprovechar el carácter novedoso del medio, transitar el erial con todo lo política y socialmente inquietante de los espacios por hacer, de los dispositivos por dar forma política y social. Sin embargo, ese lado estimulante tenía a su vez algo de peligroso (la sombra de la falta de creatividad que supone la repetición hegemónica). En este contexto, vamos a establecer una analogía entre el net.art y el ciberfeminismo que no es vana, no para situar nuestro mito. Ambos orígenes y trayectorias están cargadas de coincidencias y pueden resultar sugerentes para acercarnos a la ficción netiana.

En primer lugar, un aspecto común sería el gran interés con que los net. artistas y las ciberfeministas se enfrentan al medio y a la estructura horizontal de la red. Internet como espacio político y como estructura desjerarquizada ha sugerido a muchos la idea de una colectividad utópica, constituida como esfera pública compuesta por todos los seres humanos, todos conectados a una gran red. No obstante, si bien la estructura horizontal del medio incitaba a lo mejor de nosotros a imaginar ideales estados de convivencia como ése (libre circulación de la información y desarrollo de una democracia efectiva), graves dificultades se cernían sobre las luchas políticas a este respecto. Una de ellas sería el hecho de que los sistemas genealógicos sobre los que se estaba construyendo el ciberespacio seguían (siguen) repitiendo los patrones de intercambio sociosimbólicos patriarcales. Escondidos tras una estructura desjerarquizada se idean nuevas y más sutiles estrategias de jerarquización y se dedican grandes esfuerzos a repetir la historia, a mantener las mismas formas de poder en lo social y también en lo artístico.

En segundo lugar, los continuos intentos por evitar inscripciones y metodologías propias de una lógica logocéntrica del discurso y, en consecuencia, los constantes rechazos a su autodefinición. El ciberfeminismo esquivaba «las trampas de la definición con diferentes actitudes hacia el arte, la cultura, la teoría, la política, la comunicación y la tecnología -el territorio de Internet-» ${ }^{10}$. Las ciberfeministas dedicaron varias sesiones de trabajo en la I Internacional Ciberfeminista de Kassel a debatir la cuestión; teniendo en cuenta que el encuentro se desarrolló dentro del Hybrid Work Space de la Documenta X no puede pasarnos desapercibida la profunda vinculación artística de las bases y propuestas de los encuentros ciberfeministas. Concretamente lo que surgió de estos debates fue un intento de definir el término por rechazo (recordemos las famosas $100 \mathrm{An}$ títesis de las $\mathrm{OBN}$ ). En esta línea, "la (auto)definición puede ser una propiedad emergente que surja de la práctica y cambie con los movimientos de deseo y acción. La definición puede ser fluida y afirmativa -una declaración de estra-

10. WILDING, F.: ¿Dónde está el feminismo en el ciberfeminismo?, www.2-red.net/habitar/ 
tegias, acciones, y objetivos", indicaba Wilding ${ }^{11}$. En sus manifiestos dejaron constancia de un elemento fundamental para esta dificultad conceptual y también para la acción política más efectiva: «se puede crear una solidaridad crucial en el hogar de la diferencia - la solidaridad, más que la unidad o el consensola solidaridad como base para una acción política efectiva» ${ }^{12}$.

De otro lado, la resistencia a la inscripción desde el net.art tendría mucho que ver con el ciberfeminismo, sobre todo en sus pretensiones políticas. Sin ir más lejos, en un principio el net.art se presentaba como una práctica artística donde se revivían las esperanzas emancipadoras del arte de las vanguardias, donde el arte parecía haber llegado (por fin) al medio ideal para su democratización y disfrute. El net.art se posicionaba, a su vez, como un signo de autorreflexividad de la época de los medios, en términos de resistencia, un «nuevo campo social donde arte y vida estarían unidos», apuntaba Rachel Greene ${ }^{13}$. Así, Internet se concebía como un espacio que facilitaba una alternativa real y crítica a las estructuras físicas y a las dinámicas de funcionamiento de la instituciónArte (con todos los lastres que ésta representaba). De hecho, en una primera lectura, lo que uniría bajo el nombre de net.art habría sido concretamente el medio técnico y la apropiación de las singularidades ontológicas de la red (algunos han proclamado que justo lo que más interesa del net.art es Internet $\mathrm{o}$, cuando menos, lo que sobre Internet advierte).

Sin embargo el net.art no se caracterizaba solamente por lo que de "nuevo» tenía, sino que ha coincidido con otras prácticas artísticas que le preceden en propósitos, tales como la lucha política por lograr la conversión de los medios en instrumentos para la democracia y la creatividad y no en "mecanismos de opresión simbólica» ${ }^{14}$. En este sentido, podríamos decir que, como el mito netiana o como el ciberfeminismo, habita un territorio de tradición crítica, en este caso dentro del resto de prácticas artísticas del siglo XX con las que establece una relación de intercambio que refuerza su carácter abierto. De la misma manera, el net.art se verifica todavía heredero, no sólo de la crítica a la InstituciónArte y a los sistemas convencionales de exposición y distribución artística, sino también de los cambios suscitados por la pérdida del aura y la fácil reproductibilidad de las obras, por el cuestionamiento de muchas ideas propias del arte de los objetos. Heredero también de las mismas contradicciones en su relación con el mercado. No sería nueva pues esta intencionalidad que aparece en Internet (y que hemos visto también en otros medios) y sobre la que muchos artistas han basado su trabajo crítico y activista. De hecho, parece condenada a aparecer y, si hacemos caso a la experiencia, condenada también a ser neutralizada por las condiciones de supervivencia del artista y por el establishment de la institución. Sí sería nuevo, sin embargo, el ciclo que suscita una manera de organizar nues-

11. Ibid.

12. Ibid.

13. GREENE, Rachel: «Web work: a history of Internet Art», ARTFORUM International, 9 (May 2000), pp. $162-167$ y 190.

14. BOURDIEU, Pierre: Sobre la televisión, Anagrama, Barcelona. 1997, p. 11. 
tra forma de conocer y experimentar el mundo a través de las imágenes y la máquina. Sería nueva la confluencia simbólica de los espacios afectados por la desubicación que opera la interfaz, no sólo el espacio físico delimitado como público o privado sino también las esferas de producción, recepción y distribución, hasta entonces limitadas a territorios diferenciados. Nueva también esta forma de experimentar el mundo que irradia la cultura de los medios, en cuyo contexto se produce Internet, y en cuya trama hemos de plantear toda reflexión sobre el net.art y también sobre las netianas. Una experimentación donde la sensación de pensamiento veloz sería desmantelada por el descubrimiento de una estructura (no reflexiva) repleta de ideas preconcebidas. Así, el net.art ha actuado como una forma de resistencia, una resistencia que desestabiliza la crisis a la que los medios someten a la esfera de producción cultural y al pensamiento.

En esta línea, podríamos identificar los primeros propósitos del net.art como práctica política como propósitos «netianas». El net.art operaba subversivamente ante la velocidad de los medios y la imposición del capital, sugiriendo y visibilizando las estrategias de repetición y homogeneización del mundo a través de los mismos. De hecho, desde las prácticas artísticas de la red se reivindicaba una transformación paralela de las instituciones que gestionan la recepción y distribución del arte. De esta forma, uno de los rasgos a tener en cuenta sería la disolución on line de estos espacios de producción, recepción y distribución (estudio, galería, museo...) y, por tanto, la disolución de las adscripciones que éstos tenían al artista hombre (con lo que ello supone para la reivindicación feminista).

Pero la máquina-interfaz donde se produce el net.art y donde se inspira el ciberfeminismo se ha posicionado no sólo como territorio de recepción estética, distribución y producción artística, sino que además se ha convertido en instrumento para la producción de subjetividad, en «rostro vacío» donde se produce la identidad, donde se hacen netianas. Si tenemos en cuenta que Internet funciona como un nuevo agente especulativo de la identidad y de otras formas de avenencia de la diversidad (formas no esenciales, desmaterializadas, fluidas y periféricas) observamos cómo estas condiciones conformarían unas prácticas artísticas que no se establecen como mecanismos de reproducción de la vida sino como medios de producción de nuevas formas de vida. Así, las netianas no podrían entenderse sino en este contexto productivo.

Por otra parte, esta cercanía sugerente y cómplice entre net.art y ciberfeminismo no puede obviar la relación entre algunos de los fracasos de ambos fenómenos. Si del net.art podemos mencionar su conflictiva y contradictoria relación con las instituciones, del ciberfeminismo podríamos hacer referencia a la desilusión por apenas poder introducir sus debates en foros no específicos, más allá de los grupos feministas.

La crítica-dependencia del net.art hacia las instituciones y la tendencia a no arriesgar demasiado en sus reivindicaciones (no sea que se le vuelva encima como una estrategia fatal y que por fin, después de tanto fingir que se moría, el arte y el artista pasen de verdad a la historia) le ha llevado, por una parte a claudicar a la conversión de muchas obras en piezas estancas de galerías y museos y, por 
otra, a que algunas de las instituciones que habían apostado por estas prácticas hayan rechazado o clausurado sus proyectos de producción y promoción de net.art, por no considerarlos ya válidos u oportunos para sus espacios.

Esta situación ha obligado a que muchos net.artistas hayan cedido a la escritura de una historia convencional, a la solicitud de sus obras para formar parte de colecciones de museos y centros de arte. Tal vez éste sea un gesto de normalidad (cuando menos, dando un vistazo a la historia del arte no nos sorprende); de hecho, se viene repitiendo periódicamente a lo largo de todo el siglo XX con todo tipo de prácticas artísticas que dejan de estar a «la última». Cuántas veces hemos visto que para "no estar» primero hay que "estar», aparecer para anunciar la desaparición, teniendo en cuenta que desde hace unas décadas "aparecer» como «ser» supone «estar» en los medios y sólo desde ellos anunciar la marcha. No obstante, no deja de llamar nuestra atención que una de las singularidades de estas prácticas (su carácter abierto) sea neutralizada por su conversión en prácticas artísticas «convencionales» $y$, por otra parte, que una de las ventajas del net.art (su acceso y distribución pública y gratuita en el mismo espacio donde se produce) tenga en algunos casos como respuesta la privatización (y elitización) mediante intranets o adaptaciones «objetuales» del net.art listas para ser vendidas o expuestas según la norma (Alli donde crece el peligro...).

De otro lado, en el ciberfeminismo, se produce un desencanto de otra índole pero que también parece restarle eficacia. Se trataría de que su infiltración en los estamentos que el poder crea para su legitimación pública no haya logrado modificar a estos estamentos $y$, en muchos casos, ni siquiera haya logrado entrar. Este último sería el caso de algunas frustraciones del debate ciberfeminista, convertido en minoritario cuando por su carácter político debe ser público y lograr afectar en la sociedad (no sólo en colectivos ya concienciados). Recordemos lo acontecido en junio de 1996 cuando Anne de Haan envió el irónico manifiesto The vagina is the boss on the Internet a la prestigiosa lista de correo sobre net.crítica Nettime, con intención de generar un debate abierto sobre el mismo. En breve los moderadores de la lista animaron a las interesadas a llevar el debate a las listas especializadas en feminismo. Cuestión que se repite con otros debates feministas que cuando se intentan sacar de los círculos donde se generan, son devueltos por sus responsables al contexto del que salieron. Esta limitación invalidaría la eficacia de muchas acciones feministas y de cualquier otra lucha política cuya pretensión pasa por ejercer cambios en la sociedad.

Vemos que en ambos casos se trata de dificultades generadas por sus respectivos intentos y estrategias de infiltración y cambio (ya sea a través de las instituciones en el caso del net.art, como a través de los foros públicos no específicos en el caso del ciberfeminismo). Estrategias que no logran modificar, a veces incluso ni siquiera acceder a aquellos espacios en los que penetran. Éste sería un reto aún pendiente en ambos contextos.

Esta posibilidad de infiltración no es sino un intento por cruzar fronteras, una tentativa que nos devuelve a las primeras relaciones que establecíamos en nuestro acercamiento a las netianas a través de la analogía entre ciberfeminismo y net.art. Recordemos cómo la singularidad creativa de la netiana que habita en 
Internet (ficción ciberfeminista) es la creatividad del que «cruza un límite» cuyo rebasamiento no sólo nos permite llegar a tiempos y espacios diferentes, sino también cruzar los límites del mismo cuerpo, las fronteras del mismo rostro y los límites de los objetos. ¿Acaso el net.art, ese estado intermedio entre el arte de los objetos y el arte "que vendrá», no deviene también mujer en ese estado creativo? :Acaso el arte, en la era de la deslocalización y la digitalización, no está donde ha estado la mujer históricamente, donde se sitúa la feminidad y el cuerpo desaparece, donde la digitalización y las redes convierten la práctica artística net.art en práctica deslocalizada ${ }^{15}$ ?

Puede que, en este contexto, el net.art devenga netiana, o puede que ambos (net.art y netiana) coincidan en el anuncio de algo que está por venir y que ellos advierten. Puede que, como apuntaba Benjamin, cada estación lleve en sus últimas creaciones una señal secreta de las cosas futuras, y quien aprendiere a leerlas no sólo podría conocer anticipadamente algo de las nuevas corrientes artísticas, sino también de los nuevos códigos, de las guerras por venir, de las nuevas revoluciones. La netiana, esa entidad facticia que se opone a lo dominante, esa nueva figuración que advierte sobre lo que la red supone para el sujeto contemporáneo mujer en una época de deslocalización, se "alza» irónica bajo las yemas de vuestros dedos, quien aprendiere a «leerlas» tal vez pueda advertir algo sobre las nuevas maneras de "ser» $y$ «hacer» mujer en el futuro on line que nos espera.

\section{DEL CIELO INTERNET A, B, C, D... DE LAS NETIANAS}

D) No hay calcificación de las netianas que no sea parcial y facticia, en efecto, pero la imposibilidad de ponerles un cuerpo perenne no puede disuadirnos de ver lo que con ellas circula y se esconde en la red, de valorar las nuevas condiciones políticas que para las mujeres y para nuestros «otros» anuncian.

B) Internet por sí sola no facilitará la emancipación de la mujer, ni siquiera una nueva representación de la mujer. Para lograr una nueva representación de lo que somos precisamos un importante esfuerzo de igualdad sexual y un constante ejercicio de imaginación e ironía. El éxito de la tecnología sólo puede ir unido a un cambio en las maneras de pensarnos.

A) La inspiradora consideración simbólica de la horizontalidad de las estructuras en red igualando feminización a digitalización no debe menospreciarse. No obstante, no podemos obviar que los sistemas genealógicos sobre los que se está construyendo el ciberespacio son eminentemente masculinos. Las ne-

15. «La cuestión es entonces hasta qué punto puede el arte ser dislocado, deslocalizado [...]. Hemos pasado de la dislocación espacial —en el arte abstracto y el cubismo- hasta la dislocación temporal que ahora está en curso. Esto representa la virtualización en su misma esencia: la virtualización de las acciones "mientras suceden» y no simplemente de lo que ya fue, recordando la idea de Barthes. No es la virtualización de la fotografía, de la reproducción o del cine; no se produce ya en tiempo diferido, sino en tiempo real», en VIRILIO, Paul y DAVID, Catherine: "Alles Fertig: se acabó (una conversación)», Acción Paralela, 3 (1997), Cuenca, http://www.accpar.org/ numero3/virilio.htm 
tianas advierten del mantenimiento (soterrado o explícito) en Internet de los ejercicios de poder y vulnerabilidad basados en dichos sistemas, y de ello se deriva una dificultad añadida, el uso de lo nuevo como bandera de un cambio ficticio, modificar la apariencia y ampliar la velocidad para seguir repitiendo las viejas formas y los viejos lenguajes de poder, los mismos estereotipos y asignaciones sexuales, acentuados más si cabe por la liberación libidinal que da el anonimato.

C) La inmersión en el mundo virtual tiene su precio. Internet puede ser tan singular como repetitivo, tan heterogéneo como homogeneizado, tan violento como aburrido. Bajo la apariencia de Internet como un medio eminentemente democrático se deslizan las mismas estrategias de poder de una parte de la humanidad sobre la otra. El desafío netiana se plantea la necesidad de articular nuevas alianzas entre la mujer y la tecnología que subviertan estas estrategias, nuevas redes donde prevalezcan el carácter público de la información, la accesibilidad, el debate crítico y el tiempo, la participación colectiva y la resistencia a la producción de netianas «fabulosas». No sin motivo, para las mujeres estar en Internet ha tenido desde sus primeros años un valor añadido, la sensación de que los espacios por hacer ofrecen más posibilidades para la no repetición de los viejos modelos de jerarquización social, más posibilidades para imaginar las nuevas condiciones creativas, sociales y políticas de un mundo en red.

E) Si todo proyecto de emancipación contemporáneo precisa una revolución científica y técnica anterior, toda propuesta efectiva de emancipación a través de la tecnología ha de pasar por estrategias de infiltración y modificación del poder (sería clave netiana). Las netianas reivindican la presencia de la mujer no sólo como usuaria de tecnología sino, de manera especial, como participante activa en las políticas de producción y distribución del hardware y del software y en las políticas sociales y educativas vinculadas a la misma.

J) El talante rizomático de Internet, propio de una red de comunicación horizontal y desjerarquizada, nos lleva a considerarla como un medio propicio para la producción de nuevas formas de subjetividad, fluidas, periféricas, posthumanas... La posibilidad de establecer relaciones intersubjetivas a través de un interfaz plantea para el sujeto la posibilidad de "maquillar(se)» y anular o multiplicar su rostro (se apunta entonces a un territorio familiar para la considerada feminidad de las mujeres). En ese trance las asignaciones estereotípicas quedarían desmanteladas en su estructura más elemental: la física (sugiriéndose la edad, la raza, el sexo... como algo contingente y provisional). En los territorios Google, chat, blog, web, e-mail..., habitaciones similares por donde pasan las netianas, se estimularía la liberación de nuestras energías subjetivas allí donde las interferencias entre los discursos pasan a convertirse en ámbitos productivos para la subjetividad.

H) La emancipación de la mujer en las sociedades avanzadas ha ido acompañada de un mayor acercamiento a los ámbitos donde históricamente se ha detentado el poder. En el caso de la tecnología (cuyo acercamiento ha estado normalmente mediado por el trabajo) está motivado por la incorporación laboral de la mujer a ámbitos distintos a los de la mera acción repetitiva mediada 
por máquinas (maquiladoras, tecleadoras y engranajes en los niveles más bajos de las cadenas de producción) y por el aumento del trabajo inmaterial mediado por redes de comunicación (teletrabajo). Esta emancipación de la mujer a través del uso tecnológico tiene distintas lecturas. De un lado, la determinación de distintos roles de los sujetos en función de su género (partiendo de su consideración como productores propia de un sistema capitalista) facilita la producción y el mantenimiento de los estereotipos de hombres y mujeres y las asignaciones que los sistemas tradicionales quieren conservar. Por otra parte, la reconfiguración de los espacios donde convencionalmente se han desarrollado y diferenciado las actividades públicas de las privadas motiva la necesidad de repensar ambas esferas ahora unidas en un espacio donde también confluyen la producción, recepción y distribución de conocimiento.

L) Las tecnologías son producto y propósito de espectros del poder codificados cultural y socialmente, están fuertemente reguladas a nivel ideológico y también cultural. Estos espectros forjados y fortalecidos durante siglos de patriarcado forman parte de las tecnologías y también de nuestras identidades $y$ de nuestros cuerpos. Asistimos a un momento de desajuste entre las posibilidades que Internet plantea (las que imaginamos) y la realidad (espectral) que nos es dada. Sin embargo, este desajuste no tiene su origen en el mundo virtual y sus responsables no son avatares de internautas ni «netianas Microsoft». Enfrentar este desajuste requiere generar «tiempos» que resistan la velocidad de los medios, "tiempos» que nos ayuden a deconstruir el "fantasma» que envuelve ya, como pátina endurecida, las estructuras físicas y sociales donde se piensa y produce la tecnología.

K) En un momento en que resultan incontrolables las transformaciones de las estructuras familiares y sociales por la convivencia de distintas culturas y realidades dentro y fuera de Internet, la cultura en red se esboza clave para el desarrollo de un pensamiento crítico y creativo sobre lo que podemos ser y hacer en el mundo. Uno de los retos que en esta línea se plantean las netianas supone facilitar la creación de fusiones netartianas como una más íntima cooperación del compromiso político feminista con la mejor creatividad e ironía de las producciones (antes artísticas) que todos los conectados podemos ya idear y hacer públicas. El net.art más político y las netianas más míticas parecen además coincidir en el anuncio de un tiempo que está por venir y que ellos advierten.

Puede haber en el alma de las netianas matices más intensos, escondidos y prodigiosos que los colores de una puesta de sol reflejada en el cristal de una prisión. Ninguna combinación arbitraria de palabras podrá representar con rigor esos colores, aunque tal vez en los intersticios digitales de su ambigüedad pueda sugerirles leves destellos de su intensidad como sujeto, de su deseo y de su destino al n(h)acer mujer en Internet. ${ }^{16}$

Fecha de recepción: 27-03-2008

Fecha de aceptación: 02-05-2008

16. Fragmentos extraídos y revisados del original: ZAFRA, Remedios; Netianas. N(h)acer mujer en Internet. Madrid, Lengua de Trapo, Colección Desórdenes, 2005. 